\title{
Association of the bovine major histocompatibility complex (BoLA) BoLA-DRB3 gene with fat and protein production and somatic cell score in Brazilian Gyr dairy cattle (Bos indicus)
}

\author{
Carlos Souza do Nascimento ${ }^{1}$, Marco Antonio Machado ${ }^{1}$, Mario Luiz Martinez ${ }^{1}$, \\ Marcos Vinícius G. Barbosa da Silva ${ }^{1}$, Marta Fonseca Martins Guimarães ${ }^{1}$, Ana Lúcia Campos ${ }^{1}$, \\ Ana Luisa Sousa Azevedo ${ }^{1}$, Roberto Luiz Teodoro ${ }^{1}$, Rui da Silva Verneque ${ }^{1}$, \\ Simone Eliza Facioni Guimarães ${ }^{2}$ and Denise Aparecida Andrade Oliveira ${ }^{3}$ \\ ${ }^{1}$ Embrapa Gado de Leite, Juiz de Fora, MG, Brazil. \\ ${ }^{2}$ Departamento de Zootecnia, Universidade Federal de Viçosa, Viçosa, MG, Brazil. \\ ${ }^{3}$ Departamento de Zootecnia, Escola de Veterinária, Universidade Federal de Minas Gerais, Belo \\ Horizonte, MG, Brazil.
}

\begin{abstract}
The effect of the bovine major histocompatibility complex (BoLA) locus on animal health may be due to a direct action of its alleles on immune functions, whereas its indirect effect on production traits might be explained by the better general health conditions of more productive animals. In the present study, the BoLA-DRB3 gene was investigated in 1058 cows belonging to seven Brazilian Gyr Dairy herds (Bos indicus, Zebu cattle). A total of 37 alleles were identified, 15 of them described for the first time in a Zebu breed. A highly significant association $(p<0.02)$ was observed between allele ${ }^{*} 54$ and a decrease $(-26.1 \mathrm{~kg})$ in milk protein yield and there was a significant association $(p<0.05)$ between this allele and lower $(-26.07 \mathrm{~kg})$ milk fat yield. There was also a significant association $(p<0.05)$ between allele ${ }^{*} 6$ and decreased $(-12.47 \mathrm{~kg})$ milk protein and allele ${ }^{*} 7$ and increased $(12.72 \mathrm{~kg})$ milk protein. There were also indications of association $(p<0.10)$ between somatic cell score (SCS) and alleles *3 (SCS increased by 0.54 units) and *31 (SCS increased by 0.46 units). The highly significant association of allele * 54 with lower protein yield suggests the possible use of this allele in marker-assisted selection programs.
\end{abstract}

Key words: cattle, marker-assisted selection, molecular markers, PCR-RFLP.

Received: October 18, 2005; Accepted: May 2, 2006.

\section{Introduction}

Dairy cattle improvement has been directed for a long time at increasing milk production, while traits related to disease resistance have been ignored. This intense selection for production traits has led to an increase in the incidence of diseases such as mastitis in dairy cattle (Van Dorp et al., 1999), the most important disease in dairy cattle breeding because of its high prevalence and associated economic loss (Owen et al., 2000). The costs associated with mastitis include those represented by milk discarding, medications and veterinary care, increased management and the decline in the amount and quality of milk and manufactured milk products (DeGraves and Fetrow, 1993). Approximately $75 \%$ of the production losses due to subclinical mastitis re-

Send correspondence to Marco A. Machado. Empresa Brasileira de Pesquisa Agropecuária, Embrapa Gado de Leite, Rua Eugênio do Nascimento 610, 36038-330 Juiz de Fora, MG, Brazil. E-mail: machado@cnpgl.embrapa.br. sult from decreased milk production (Colleu and Le Bihan-Duval, 1995). Production losses are associated with a reduction in milk yield and alterations in the main milk components (fat, protein, lactose, anions and cations). These changes damage the dairy industry due to the loss of processed milk and its derivatives.

Brazilian dairy cattle breeding programs have paid little attention to the selection of cattle for milk components because the emphasis of these programs has been on milk production rather than milk components. This contrasts with a world trend towards greater valorization of milk components, especially protein. Milk payment systems based on milk quality, with the inclusion of protein and fat in the payment scheme, have been adopted in developed countries and, tentatively, by some more progressive Brazilian dairy cooperatives to satisfy the increasingly demanding consumer market. 
Studies have been carried out to investigate quantitative trait loci (QTLs) that might be associated with higher milk, fat and protein yields, and some methods to identify these QTLs have been developed. A wide variety of methods including genome scanning with microsatellite markers and the study of specific candidate genes, such as the bovine major histocompatibility complex (BoLA), have been employed. The use of molecular techniques may help overcome some of the limitations of current breeding methods.

Molecular techniques are able to detect variations or polymorphisms in specific DNA regions among different members of a population. These polymorphisms can be used to construct genetic maps and to determine differences between markers in the expression of particular phenotypes in a population. These differences, in turn, might indicate a direct effect of these markers on the genetic determination of a trait (Albert et al., 1994).

Several studies have tried to identify associations between genetic polymorphisms and important economic traits. In dairy cattle, production traits and traits related to animal health have been associated with allelic polymorphisms in the BoLA gene (Arriens et al., 1996; Maillard et al., 1996; Dietz et al., 1997; Kelm et al., 1997; Starkenburg et al., 1997; Sharif et al., 1998). Associations have been observed between the BoLA gene and differences in the production and percentage of milk fat and protein, growth rate, reproductive performance, immune response, and disease resistance. Since the genes of the BoLA complex are extremely polymorphic, they might be useful in markerassisted selection. However, such investigations have produced conflicting results and suggest the need for further association studies in larger populations.

The objective of the present study was to genetically characterize BoLA-DRB3 alleles in herds belonging to the Brazilian National Gyr Dairy Breeding Program, and to determine associations between these alleles and milk protein and fat production traits and somatic cell score (SCS).

\section{Material and Methods}

The phenotypic data used in the present study were obtained from the Brazilian National Gyr Dairy Breeding Program managed by the Dairy Cattle Research Center of the Brazilian agricultural company Empresa Brasileira de Pesquisa Agropecuária (Embrapa). Data regarding 305day milk, fat and protein yields and somatic cell counts were obtained for the first three lactations of $1076 \mathrm{Gyr}$ (Bos indicus) cows, the daughters of 99 sires, which had calved between 1987 and 2004. The cows studied were from seven Gyr herds (coded as herds 249, 270, 266, 264, 265, 277 and 2021) from different regions in the Brazilian state of Minas Gerais, and had similar genetic backgrounds since the herds had been selected for milk yield for more than 50 years $(\cong 8$ generations), albeit at different selection intensities. The number of cows sampled (n) from each heard were as fol- lows: 414 from herd 249; 236 from herd 265; 160 from herd 264; 85 from herd 266; 67 from herd 277; 61 from herd 2021; and 53 from herd 270. The contemporary groups were characterized (coded) by a combination of herd, year and calving season.

Blood samples were collected from the $1076 \mathrm{Gyr}$ cows between 2000 and 2004 and sent to the Molecular Genetics Laboratory of Embrapa Dairy Cattle for DNA extraction and genotyping of the BoLA-DRB3 gene. Leukocytes were separated from fresh whole blood by transferring approximately $1.0 \mathrm{~mL}$ of the blood sample to $2-\mathrm{mL}$ microcentrifuge tubes and washing the sample with lysis buffer until a white pellet without red blood cell residue was obtained. These cells were stored frozen at $-70{ }^{\circ} \mathrm{C}$ until the time of DNA extraction. The leukocytes were treated with saline and proteinase $K$, and protein was removed by phenol-chloroform treatment. The quality and concentration of the DNA were determined with the Gene Quant Pro spectrophotometer (Amersham Biosciences).

The amplification of the 284-bp fragment of the BoLA-DRB3 gene was performed in two steps. In the first step, the HLO30 (5'-ATCCTCTCTGCAGCACATTTCC-3 ') and HLO31 primers (5'-TTAAATTCGCGCTCACC TCGCCGCT- 3 ') were used and in the second step the HLO30 and HLO32 primers (5'-TCGCCGCTGCCACA GT-3') were used, the HLO32 primer containing all the nucleotides of the 3' end of exon 2 of the BoLA-DRB3 gene and 8 nucleotides overlapping with the 3 ' end of the HLO31 primer. The use of these primers increased the PCR specificity and reduced the presence of nonspecific fragments. The first amplification reaction consisted of $10 \mathrm{cy}-$ cles of $94{ }^{\circ} \mathrm{C}$ for $60 \mathrm{~s}, 60^{\circ} \mathrm{C}$ for $120 \mathrm{~s}$ and $72{ }^{\circ} \mathrm{C}$ for $60 \mathrm{~s}$. The reaction mixture contained approximately $12.5 \mathrm{ng}$ DNA $(2.5 \mu \mathrm{L}), 1 \mathrm{U}$ of Taq DNA polymerase, $100 \mu \mathrm{M}$ of dNTPs, $0.2 \mu \mathrm{M}$ of each primer, $10 \mathrm{mM}$ Tris- $\mathrm{HCl}, \mathrm{pH} 8.0$, $2.5 \mathrm{mM} \mathrm{MgCl}_{2}$ and $50 \mathrm{mM} \mathrm{KCl}$ in a final volume of $10 \mu \mathrm{L}$. The second amplification reaction consisted of 30 cycles of $94{ }^{\circ} \mathrm{C}$ for $60 \mathrm{~s}$ and $65^{\circ} \mathrm{C}$ for $30 \mathrm{~s}$ using $1.4 \mu \mathrm{L}$ of the first reaction as template in a final volume of $35 \mu \mathrm{L}$. Each PCR contained $1 \mathrm{U}$ of Taq DNA polymerase, $100 \mu \mathrm{M}$ of dNTPs, $0.2 \mu \mathrm{M}$ of each primer, $10 \mathrm{mM}$ Tris- $\mathrm{HCl}, \mathrm{pH} 8.0,2.5 \mathrm{mM}$ $\mathrm{MgCl}_{2}$ and $50 \mathrm{mM} \mathrm{KCl}$. The amplification reactions were performed in a GeneAmp PCR-System 9600 (Applied Biosystems).

The PCR products generated in the second amplification were resolved by $5 \%$ nondenaturing polyacrylamide gel (29:1 acrylamide:bis-acrylamyde) electrophoresis at $500 \mathrm{~V}$ for $1 \mathrm{~h}$. The nondenaturing polyacrylamide gel were stained with silver nitrate and the amplification products were standardized by diluting the amplified sample in $\mathrm{TE}_{0.1}$ to the same amount of DNA. The amplification reaction produced a 284-bp fragment of the exon 2 of the BoLADRB3 gene, confirmed by DNA sequencing. 
The polymerase chain reaction using restriction fragment length polymorphism (PCR-RFLP) was carried out as described by van Eijk et al. (1992). The amplified fragment was digested separately with the Rsa I, Hae III and Bst YI restriction enzymes (van Eijk et al., 1992) and submitted to a pre-run at 800 volts for $40 \mathrm{~min}$ to guarantee better visualization of the digested products. The digestion products were resolved by $12 \%$ non-denaturing polyacrylamide gel (29:1 acrylamide:bis-acrylamide) electrophoresis at $800 \mathrm{~V}$ for $3 \mathrm{~h}$ using $35-\mathrm{cm}$ plates to permit a perfect separation of the DNA fragments and to guarantee unequivocal identification of the alleles. The gels were stained with silver nitrate and the fragments identified by comparison with 10and 25-bp standards.

Herds with less than four records were excluded from the analyses. Animals whose phenotypic data regarding fat and milk production traits and somatic cell score (SCS) had been lost were disregarded with the result that 1723 fat production records, 1607 protein production records, and 1078 SCS records of the first three lactations of 1038 cows remained.

Since the somatic cell counts (SCC) were not normally distributed the SCC for each animal were $\log _{10}$ transformed and converted into a SCS using the following expression (NMC, 1996):

$$
S C S=\left(\frac{\ln \left(\frac{S C C}{100}\right)}{0.693147}\right)+3
$$

The allele frequencies of the DRB3 gene were calculated by direct counting. To obtain a higher data consistency for the association studies, data from animals showing a frequency of $1 \%$ or less within the BoLA allele class were eliminated from the respective analysis involving each of these groups. A total of 1076 animals were genotyped for the BoLA-DRB3 gene and 2138 alleles could be identified. The combination of phenotypic and genotypic data reduced the number of animals to be considered for analysis to 1058. Therefore, animals with the following BoLA-DRB3 alleles were excluded: $* 4, * 8, * 9$, $* 10, * 12, * 19, * 22, * 23, * 24, * 26, * 28, * 33, * 34, * 36, * 38$, $* 41, * 45, * 46, * 47$, and $* 52$.

Statistical analysis was performed using algorithms available in the MTDFREML computer package (Boldman et al., 1995). Data regarding fat and protein yields and SCS were analyzed using a standard animal model as proposed by Israel and Weller (1998).

For estimation of the direct effect of each allele, the phenotypic records were analyzed using a gene substitution model, which considered the additive effect of an allele of the BoLA gene (Israel C and Weller JI, 1998).

This model can be represented in the form of a matrix as follows:

$$
y=X h+M m+Z_{1} a+Z_{2} p+\varepsilon
$$

where $y=$ vector of observations; $X, Z_{1}$ and $Z_{2}=$ incidence matrices referring to fixed and random (additive genetic, permanent environmental and residual) effects; $h, a, p$ and $\varepsilon=$ vectors of solutions for the fixed, additive genetic, permanent environmental and residual effects, respectively; $M=$ matrix containing 0,1 or 2 corresponding to the number of copies of a given BoLA-DRB3 allele present in each individual; $m$ = vector including the fixed effects of gene substitution for different BoLA-DRB3 alleles represented by regression coefficients.

The effects of herd, year, calving season and the age of the cow at calving were assumed to be fixed and the additive genetic, permanent environmental and residual effects were assumed to be random and normally distributed, with means of zero and variances of $\sigma_{a}^{2}, \sigma_{p}^{2}$ and $\sigma_{e}^{2}$, respectively.

The mixed model equations used for the model were:

$\left[\begin{array}{cccc}X^{\prime} X & X^{\prime} M & X^{\prime} Z_{1} & X^{\prime} Z_{2} \\ M^{\prime} X & M^{\prime} M & M^{\prime} Z_{1} & M^{\prime} Z_{2} \\ Z_{1}^{\prime} X & Z_{1}^{\prime} M & Z_{1}^{\prime} Z_{1}+\lambda A^{-1} & Z_{1}^{\prime} Z_{2} \\ Z_{2}^{\prime} X & Z_{2}^{\prime} M & Z_{2}^{\prime} Z_{1} & Z_{2}^{\prime} Z_{2}+\gamma\end{array}\right]\left[\begin{array}{l}\hat{h} \\ \hat{m} \\ \hat{a} \\ \hat{p}\end{array}\right]=\left[\begin{array}{c}X^{\prime} y \\ M^{\prime} y \\ Z_{1}^{\prime} y \\ Z_{2}^{\prime} y\end{array}\right]$

where $\lambda=\sigma_{e}^{2} / \sigma_{a}^{2}, \gamma=\sigma_{e}^{2} / \sigma_{p}^{2}$ and $A^{-1}$ is the inverse of the relationship matrix. Data from 29,894 known ancestor were included in the pedigree in order to construct a relationship matrix for the 1058 cows with phenotypic and genotypic data.

This gene substitution model expresses the effect of a particular allele after removal of the additive effects of other alleles. Significance of associations was determined for each trait separately by an $F$-test.

\section{Results}

The distribution of the allele frequencies of the BoLA-DRB3 gene polymorphisms for the seven herds is shown in Table 1. The restriction pattern analyses used the patterns described by van Eijk et al. (1992), of which we detected all five BstYI patterns, five of the nine HaeIII patterns and 19 out of the $25 \mathrm{RsaI}$ patterns. Using a combination of the different restriction patterns of the three enzymes, van Eijk et al. (1992) detected 54 different alleles, of which we identified 37 in the seven herds of the present study.

The allele frequencies ranged from $0.05 \%$ to $19.04 \%$ and the sum of the frequencies of the six most common alleles (BoLA-DRB3*16, *20, *27, *29, *35 and *54) was $64.59 \%$ of all alleles found in the population (Table 1). The number of different alleles detected in each herd were: 29 in herd $249(n=414$ cows); 24 in herd $266(n=85): 23$ in herd $264(\mathrm{n}=160) ; 19$ in herd $277(\mathrm{n}=67) ; 19$ in herd 2021 $(\mathrm{n}=61)$; and 18 in herd $265(\mathrm{n}=236)$, and 16 in herd 270 $(\mathrm{n}=53)$. 
Table 1 - Allele frequency of the BoLA-DRB3 gene obtained for $1076 \mathrm{Gyr}$ cows distributed among the seven herds analyzed.

\begin{tabular}{|c|c|c|c|c|c|c|c|c|}
\hline \multirow{2}{*}{$\begin{array}{l}\text { BoLA-DR } \\
\text { B3 allele }\end{array}$} & \multicolumn{8}{|c|}{ Herd } \\
\hline & $249(n=414)$ & $264(n=160)$ & $265(\mathrm{n}=236)$ & $266(\mathrm{n}=85)$ & $270(\mathrm{n}=53)$ & $277(\mathrm{n}=67)$ & $2021(\mathrm{n}=61)$ & Total $(n=1076)$ \\
\hline$* 3$ & 2.78 & 5.08 & 0.64 & 8.93 & - & 2.27 & - & 2.81 \\
\hline$* 4$ & 0.24 & - & - & 0.60 & - & - & - & 0.14 \\
\hline$* 5$ & 5.68 & 1.90 & 0.21 & - & 2.91 & 10.61 & 9.09 & 3.84 \\
\hline$* 6$ & 5.56 & 2.54 & 0.21 & 5.95 & 0.97 & 2.27 & 0.83 & 3.27 \\
\hline$* 7$ & 0.97 & 1.90 & 14.65 & 1.19 & 2.91 & 2.27 & 3.31 & 4.44 \\
\hline$* 8$ & 1.21 & - & - & - & - & - & - & 0.47 \\
\hline$* 9$ & 0.24 & 0.63 & 0.21 & 0.60 & 6.80 & - & - & 0.61 \\
\hline$* 10$ & 0.12 & - & - & - & 0.97 & - & - & 0.09 \\
\hline$* 11$ & 5.68 & 0.32 & 0.42 & 1.19 & 3.88 & 0.76 & 4.96 & 2.95 \\
\hline$* 12$ & - & 0.32 & - & - & - & - & - & 0.05 \\
\hline$* 15$ & 3.14 & - & - & 0.60 & - & - & - & 1.26 \\
\hline$* 16$ & 10.63 & 10.16 & 12.31 & 10.12 & 8.74 & 12.88 & 8.26 & 10.80 \\
\hline$* 18$ & 2.17 & 4.13 & - & 2.98 & 1.94 & 3.03 & 2.48 & 2.10 \\
\hline$* 19$ & 0.24 & 2.86 & 0.64 & 2.98 & - & - & 0.83 & 0.94 \\
\hline$* 20$ & 27.42 & 14.29 & 1.49 & 20.24 & 38.83 & 20.45 & 22.31 & 19.04 \\
\hline$* 22$ & 0.12 & - & - & 0.60 & - & - & - & 0.09 \\
\hline$* 23$ & - & - & 0.42 & - & - & - & 0.83 & 0.14 \\
\hline$* 24$ & - & - & - & 0.60 & - & 0.76 & - & 0.09 \\
\hline$* 26$ & - & 0.32 & - & - & - & - & - & 0.05 \\
\hline$* 27$ & 11.71 & 18.73 & 21.02 & 7.74 & 3.88 & 19.70 & 21.49 & 15.15 \\
\hline$* 28$ & 0.36 & - & - & 0.60 & 0.97 & - & - & 0.23 \\
\hline *29 & 1.09 & 8.89 & 26.11 & 3.57 & 3.88 & 1.52 & 4.96 & 8.33 \\
\hline *31 & 6.04 & 5.08 & 0.42 & 3.57 & 7.77 & 3.03 & 4.96 & 4.30 \\
\hline$* 33$ & 0.12 & - & - & - & - & - & - & 0.05 \\
\hline$* 34$ & - & 0.32 & - & - & - & 0.76 & - & 0.09 \\
\hline$* 35$ & 6.16 & 6.35 & 7.86 & 2.98 & 10.68 & 10.61 & 4.13 & 6.69 \\
\hline *36 & - & 0.32 & - & - & - & - & - & 0.05 \\
\hline$* 38$ & 0.12 & - & - & - & - & - & - & 0.05 \\
\hline$* 41$ & 0.24 & - & - & - & - & - & - & 0.09 \\
\hline$* 42$ & 1.45 & 5.71 & 11.04 & 1.19 & 0.97 & 1.52 & 1.65 & 4.16 \\
\hline$* 45$ & - & - & - & - & - & - & 0.83 & 0.05 \\
\hline$* 46$ & 0.12 & 0.63 & - & 0.60 & - & - & - & 0.19 \\
\hline$* 47$ & 0.12 & - & - & 1.19 & - & 2.27 & 0.83 & 0.33 \\
\hline$* 48$ & 0.85 & 1.90 & 1.06 & 5.95 & - & 0.76 & 0.83 & 1.40 \\
\hline$* 51$ & 0.85 & 2.22 & - & 0.60 & - & 3.03 & 2.48 & 1.03 \\
\hline$* 52$ & - & - & 0.21 & - & - & - & - & 0.05 \\
\hline$* 54$ & 4.59 & 5.40 & 1.06 & 15.48 & 3.88 & 1.52 & 4.96 & 4.58 \\
\hline Total & 100.0 & 100.00 & 100.00 & 100.00 & 100.00 & 100.00 & 100.00 & 100.00 \\
\hline
\end{tabular}

$\mathrm{n}=$ number of animals per herd.

While 29 different alleles were observed in the 414 cows from herd 249 BoLA-DRB3 gene diversity was lower in herd 270 in which only 16 alleles were identified, although in this case the sample size of only 53 cows was low. Eleven common alleles were shared by the seven herds analyzed and the DRB $3 * 20$ allele was the most frequent allele in the seven herds combined ('the general population').

Analysis based on the mixed model equations provided the following mean yields and their respective standard deviations for the general population: fat yield $=175.07 \pm 95.03 \mathrm{~kg}$; protein yield $=116.04 \pm$ $54.86 \mathrm{~kg}$ and $\mathrm{SCS}=4.92 \pm 1.63$ units. The means for fat and protein yields and SCS according to herd are shown in Table 2.

The substitution effects of BoLA alleles are shown in Table 3 . The DRB $3 * 54$ allele showed a significant association $(p<0.05)$ with a reduction in fat yield. The effect of substitution of a copy of this allele reduced fat yield by 26.1 $\mathrm{kg}$. As can be seen in Table 1, the frequency of this allele was relatively moderate $(4.58 \%)$ in the general population 
Table 2 - Mean yield per herd for fat and protein yield $(\mathrm{kg})$ and somatic cell score (SCS) (units).

\begin{tabular}{lccc}
\hline Herd & Mean fat yield $(\mathrm{kg})$ & Mean protein yield $(\mathrm{kg})$ & SCS (units) \\
\hline 249 & $117.01(811)^{1}$ & $89.50(761)$ & $4.85(600)$ \\
265 & $261.97(552)$ & $151.13(544)$ & $5.11(288)$ \\
266 & $148.30(158)$ & $108.95(158)$ & $5.00(108)$ \\
270 & $162.21(15)$ & $139.00(15)$ & - \\
277 & $219.68(111)$ & $135.08(110)$ & $4.70(72)$ \\
2021 & $154.58(31)$ & $104.74(19)$ & $4.10(10)$ \\
\hline
\end{tabular}

${ }^{1}$ Number of observations in parenthesis.

with a high frequency of this allele (15.48\%) being observed in herd 266.

The results of univariate analysis of protein yield showed two alleles with negative effects (Table 3), a significantly lower protein yield the being associated with the DRB3*54 allele $(-20.31 \mathrm{~kg}, \mathrm{p}<0.02)$ and the DRB $3 * 6$ allele $(-12.47 \mathrm{~kg}, \mathrm{p}<0.10)$. In compensation, the presence of the DRB3*7 allele had a positive effect on protein yield $(12.72 \mathrm{~kg}, \mathrm{p}<0.10)$ in animals with this genotype.

Analysis of the effect of the BoLA alleles on SCS suggests associations $(\mathrm{p}<0.10)$ with the DRB3*3 $(0.54$ somatic cell units (SCU)) and DRB3*31 (0.46 SCU) alleles in animals carrying these alleles.

Table 3 - Substitution effects of BoLA-DRB3 alleles for fat yield (kg), protein yield $(\mathrm{kg})$ and somatic cell score (SCS, units) and their respective standard deviations (SD).

\begin{tabular}{lccc}
\hline & \multicolumn{2}{c}{ Yield } & \\
\cline { 2 - 3 } Allele & Fat $(\mathrm{kg}) \pm \mathrm{SD}$ & Protein $(\mathrm{kg}) \pm \mathrm{SD}$ & SCS (units) $\pm \mathrm{SD}$ \\
\hline$* 3$ & $-6.959 \pm 13.68$ & $-0.392 \pm 8.70$ & $0.54^{\#} \pm 0.32$ \\
$* 5$ & $-7.011 \pm 10.97$ & $-10.697 \pm 7.16$ & $-0.01 \pm 0.26$ \\
$* 6$ & $-17.006 \pm 11.11$ & $-12.476^{\#} \pm 7.26$ & $-0.18 \pm 0.26$ \\
$* 7$ & $14.004 \pm 11.14$ & $12.720^{\#} \pm 7.23$ & $0.25 \pm 0.27$ \\
$* 11$ & $-8.777 \pm 12.21$ & $-3.421 \pm 8.10$ & $0.02 \pm 0.29$ \\
$* 15$ & $6.337 \pm 13.51$ & $0.907 \pm 8.87$ & $0.18 \pm 0.33$ \\
$* 16$ & $1.021 \pm 9.03$ & $-1.953 \pm 5.87$ & $-0.05 \pm 0.22$ \\
$* 18$ & $3.690 \pm 14.98$ & $-1.362 \pm 10.17$ & $-0.10 \pm 0.38$ \\
$* 20$ & $-5.548 \pm 8.76$ & $-3.117 \pm 5.70$ & $0.10 \pm 0.21$ \\
$* 27$ & $-2.045 \pm 8.79$ & $-1.335 \pm 5.74$ & $0.14 \pm 0.21$ \\
$* 29$ & $1.157 \pm 9.68$ & $-0.977 \pm 6.33$ & $0.01 \pm 0.25$ \\
$* 31$ & $5.96 \pm 11.02$ & $5.015 \pm 7.17$ & $0.46^{\#} \pm 0.27$ \\
$* 35$ & $-6.766 \pm 9.67$ & $-4.769 \pm 6.33$ & $0.14 \pm 0.24$ \\
$* 42$ & $11.771 \pm 11.67$ & $4.352 \pm 7.62$ & $0.07 \pm 0.29$ \\
$* 48$ & $6.039 \pm 15.79$ & $0.822 \pm 10.40$ & $0.15 \pm 0.41$ \\
$* 51$ & $-13.597 \pm 18.61$ & $-18.723 \pm 12.33$ & $0.00 \pm 0.47$ \\
$* 54$ & $-26.074 \pm 11.74$ & $-20.310 * \pm 7.72$ & $-0.12 \pm 0.28$ \\
\hline & & &
\end{tabular}

$\bullet(p<0.02) ; \bullet(p<0.05) ;{ }^{*}(\mathrm{p}<0.10)$.

\section{Discussion}

The large number of alleles (37) identified in the seven herds analyzed demonstrates high polymorphism in the BoLA-DRB3 gene of Gyr cattle (Table 1). Mota et al. (2002) detected 17 different BoLA-DRB3 alleles in Brazilian dairy Gyr cattle, some of which had previously been reported in Bos indicus Brahman cattle (Maillard et al.,1999), while Machado et al. (2005) detected seven different BoLA-DRB3 alleles in Gyr cattle In the present study we have identified a further 15 BoLA-DRB3 alleles $(* 9, * 12$, $* 15, * 16, * 22, * 23, * 24, * 26, * 36, * 38, * 45, * 46, * 51, * 52$, and *54) in Brazilian Bos indicus Gyr dairy cattle. The distribution of the allele frequencies varied among herds, possibly due to variation in the founder populations, different selection intensities and/or the variable number of genotyped animals in each herd.

The presence of the DRB3*20 allele at a high frequency agrees with Mota et al. (2004) who investigated the allele frequencies of the BoLA-DRB3 gene by direct sequencing of PCR products in $28 \mathrm{Gyr}$ cows from another population. The allelic diversity found in the Gyr breed suggests the maintenance of BoLA-DRB3 gene allelic diversity during selection for production traits. High polymorphism levels have also been reported in Bos taurus breeds by Dietz et al. (1997) who found that in Holstein cows the BoLA-DRB3*8, *11,*16, *22, *23 and *24 alleles accounted for $70.3 \%$ of the total allele frequency and Gilliespie et al. (1999) who reported that in Jersey cows the sum of the BoLA-DRB $3 * 8, * 10, * 15, * 21$ and $* 36$ allele frequency was $67.8 \%$. Comparison of these results reveals that, except for the allele $* 16$ found in the breeds cited, the presence and/or frequency of alleles varies widely among breeds. In European B. taurus breeds selected for milk production, Sharif et al. (1999) observed higher frequencies of the BoLA-DRB3 $* 8$ allele in Holstein cattle while Gilliespie et al. (1999) observed higher frequencies of the BoLA-DRB3*10 allele in Jersey cows, whereas Takeshima et al. (2001) showed that the *22 allele was the most frequent BoLA-DRB3 allele in Frisian cattle.

Various studies have demonstrated significant associations between BoLA-DRB3 alleles and fat yield. Starkenburg et al. (1997) observed significant associations of the DRB $3 * 7$ and DRB3*26 alleles with lower fat yield in combined lines, and a positive association of the DRB $3 * 24$ allele with increased fat yield during first lactation in lines of Holstein cows selected for milk yield. These authors studied only 173 animals, 54 from the control line and 119 from the line selected for milk yield. The small number of animals used by these authors compared to the number of animals in our current study may have contributed to the discrepancy between their results and those obtained in our investigation. In addition, these differences may also be explained by variations in linkage disequilibrium between these alleles and a possible QTL for milk fat yield in the different breeds studied. 
In contrast to what has so fare been reported in the literature, we found that the DRB3*54 (p<0.02) and DRB3*6 ( $<<0.10)$ alleles significantly contributed to a decrease in protein yield. However, the positive effect of allele*7 $(\mathrm{p}<0.10)$ agrees with the results reported by Starkenburg et al. (1997) who also found evidence of the association of the allele DRB $3 * 8$ with lower protein yield during third lactation and of allele DRB3*26 during first and second lactation in selection lines for milk yield. Starkenburg et al. (1997) also found, conversely, that the DRB3*11 allele was associated with a significant increase $(\mathrm{p}<0.10)$ in protein yield in lines selected during the third lactation. Sharif et al. (1999) observed that the DRB3*22 allele significantly reduced protein yield $(\mathrm{p}<0.10)$ in a population of Holstein cows, whereas the DRB $3 * 8$ allele was significantly associated with increased protein yield. Again, the number of animals studied was small compared to the number analyzed in the present investigation, which would explain the conflicting results. These studies analyzed different dairy breeds, a fact that might result in variations in linkage disequilibrium between these alleles and a possible QTL for milk protein yield in the breeds investigated.

In the present study, there was only an indication of associations $(\mathrm{p}<0.10)$ with alleles DRB3*3 (2.81\%) and DRB3*31 (4.31\%) with somatic cell score. The weakly significant associations with somatic cell count and the lack of agreement of these results with previous studies may be due to different factors. Gyr and Holstein populations may differ regarding linkage disequilibrium in the BoLA genes or in other genes that influence the immune response. Another possibility is that different pathogens are present in the environment of these populations and the same allele may respond differently to alternative pathogens during various lactations. Moderate heritability $(0.19)$ was estimated between SCS and the DRB3*3 and DRB3*31 alleles, with temporary effects such as environmental pathogens probably having a marked influence on the results.

Practically all investigations aimed at identifying possible associations between BoLA-DRB3 alleles and production traits have analyzed a smaller number of of phenotypic and genotypic records than the present study with, for example, Dietz et al. (1997) having analyzed 127 records, Kelm et al. (1997) 137 and Gilliespie et al. (1999) 72 production records and this may have contributed to the conflicting findings. Mota et al. (2002) stated that a source of uncertainty regarding the BoLA-DRB3 gene is the lack of studies on $B$. indicus cattle, so the study reported in the present paper certainly contributes to a better understanding of this gene in Gyr cattle since 15 previously undetected alleles were identified.

According to Weigel et al. (1990), the potential application of BoLA alleles as markers of production traits might be less important since traditional selection is highly effective. However, this is not true for direct selection for disease resistance due to both the low heritability of this trait and the difficulty and/or complexity inherent in measuring and evaluating this trait. Thus, the application of marker-assisted selection and manipulation techniques using BoLA complex genes may help with the selection for higher disease resistance, which has as an indirect effect on increased milk yield due to the better general health conditions of the animals. The highly significant association of allele *54 with lower protein yield suggests the possible use of this allele in marker-assisted selection programs.

\section{Acknowledgments}

This study was supported by Fundação de Amparo a Pesquisa de Minas Gerais (FAPEMIG), Conselho Nacional de Desenvolvimento Tecnológico (CNPq), and Coordenadoria de Aperfeiçoamento de Ensino Superior (CAPES). The authors thank Embrapa (CNPGL) for providing the infrastructure for this study.

\section{References}

Albert B, Bray D, Lewis J, Raff MB, Roberts K and Watson JD (1994) Molecular Biology of the Cell. Garland Publishing, Inc., New York, pp 355-362.

Arriens MA, Hofer A, Obexer-Ruff G and Lazary S (1996) Associations of serologically defined BoLA class I alleles with milk-production traits in 3 Swiss cattle breeds. Livestock Production Science 45:163-169.

Boldman KG, Kriese LA, Van Vleck LD, Van Tassel CP and Kachmen SD (1995) A Manual for Use of MTDFREML- A Set of Programs to Obtain Estimates of Variances and Covariances (DRAFT). Department of Agriculture, Agricultural Research Service, Washington, D.C., 120 pp.

Colleu JJ and LE Bihan-DuvalL (1995) A simulation study of selection methods to improve mastitis resistance of dairy cows. Journal of Dairy Science 78:659-671.

Degraves FJ and Fetrow J (1993) Economics of mastitis and mastitis control. Veterinary Clinics of North America: Food Animal Practice 9:421-434.

Dietz AB, Cohen ND, Timms L and Kehrli ME (1997) Bovine lymphocyte antigen class II alleles as risk factors for high somatic cell counts in milk of lactating dairy cows. Journal of Dairy Science 80:406-412.

Gillespie BE, Jayarao BM, Dowlen HH and Oliver SP (1999) Analysis and frequency of bovine lymphocyte antigen DRB3.2 alleles in Jersey cows. Journal of Dairy Science 82:2049-2053.

Israel C and Weller JI (1998) Estimation of candidate gene effects in dairy cattle populations. Journal of Dairy Science 81:1653-1662.

Kelm SC, Dettilleux JC, Freeman AE, Kehrli Jr ME, Dietz AB, Fox LK, Butler JE, Kasckovics I and Kelley DH (1997) Genetic association between parameters of inmate immunity and measures of mastitis in periparturient Holstein cattle. Journal of Dairy Science 80:1767-1775.

Machado MA, Nascimento CS, Martinez ML, Silva MVGB da, Campos AL, Teodoro RL, Verneque RS and Guimarães SEF (2005) Associação do loco bola-drb3.2 com produção 
de leite em bovinos da raça Gyr. Arquivo Brasileiro de Medicina Veterinária e Zootecnia 57:380-389.

Maillard JC, Martinez D and Bensaid A (1996) An amino acid sequence coded by the exon 2 of the BoLA DRB3 gene associated with a BoLA class I specificity constitutes a likely genetic marker of resistance to dermatophilosis in Brahman zebu cattle of Martinique (FWI). Annals of the New York Academy of Sciences 791:185-197.

Maillard JC, Renard C, Chardon P, Chantal I and Bensaid A (1999) Characterization of 18 new BoLA-DRB3 alleles. Animal Genetics 30:200-203.

Mota AF, Gabriel JE, Martinez ML and Coutinho LL (2002) Distribution of bovine lymphocyte antigen (BoLA-DRB3) alleles in Brazilian dairy Gyr cattle (Bos indicus). European Journal of Immunogenetics 29:223-227.

Mota AF, Martinez, ML and Coutinho LL (2004) Genotyping BoLA-DRB3 alleles in Brazilian Dairy Gyr cattle (Bos indicus) by temperature-gradient gel electrophoresis (TGGE) and direct sequencing. European Journal of Immunogenetics 31:31-35.

NMC (1996) Effects of mastitis on milk production, composition, and quality, $4^{\text {th }}$ edition. In: Current Concepts of Bovine Mastitis, National Mastitis Coucil, Madison, WI, 64 pp.

Owen JB, Axford RFE and Bishop SC (2000) Mastitis in dairy cattle. In: Axford RFE, Bishop SC, Nicholas FW and Owen JB (eds) Breeding for Disease Resistance in Farm Animals. CAB International, Wallingford, pp 243-252.
Sharif S, Mallard BA, Wilkie BN, Sargeant JM, Scott HM, Dekkers JC and Leslie KE (1998) Association of the bovine major histocompatibility complex DRB3 (BoLA-DRB3) alleles with occurrence of disease and milk somatic cell score in Canadian dairy cattle. Animal Genetics 29:185-193.

Sharif S, Mallard BA, Wilkie BN, Sargeant JM, Scott HM, Dekkers JC and Leslie KE (1999) Associations of the bovine major histocompatibility complex DRB3 (BoLA) with production traits in Canadian dairy cattle. Animal Genetics 30:157-160.

Starkenburg RJ, Hansen LB, Kehrli Jr. ME and Chester-Jones H (1997) Frequencies and effects of alternative DRB3.2 alleles of bovine lymphocyte antigen for Holsteins in milk selection and control lines. Journal of Dairy Science 80:3411-3419.

Takeshima S, Ikegami M, Morita M, Nakai Y and Aida Y (2001) Identification of new cattle BoLA-DRB3 alleles by sequence-based typing. Immunogenetics 53:74-81.

Van Eijk MJT, Stewart-Haynes JA and Lewin HA (1992) Extensive polymorphism of the BoLA-DRB3 gene distinguished by PCR-RFLP. Animal Genetics 23:483-496.

Van Dorp RT, Martin SW, Shoukri MM, Noodhuizen JP and Dekkers JC (1999) Epidemiologic study of disease in 32 registered Holstein dairy herds in British Columbia. Canadian Journal of Veterinary Research 63:185-192.

Weigel KA, Freeman AE, Kehli JME, Stear MJ and Kelley DH (1990) Association of class I bovine lymphocyte complex alleles with health and production traits in dairy cattle. Journal of Dairy Science 73:2538-2546.

Associate Editor: Pedro Franklin Barbosa 